\title{
Experiencia multicéntrica en reconstrucción nerviosa del miembro inferior
}

\section{Multicentric experience in lower limb nerve reconstruction}

Leonardo ROJAS*, Carlos LACOUTURE**

Federico ÍÑIGO***, Alexander CÁRDENAS ${ }^{\star \star \star *}$

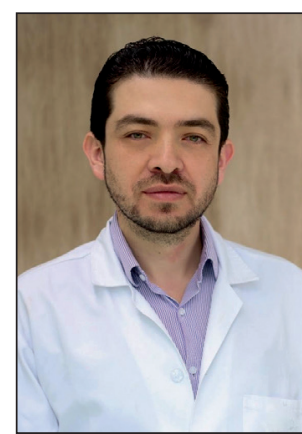

Rojas L.
Resumen

Introducción y objetivo. Las lesiones nerviosas en los miembros inferiores son un problema mayor para quienes las padecen porque ocasionan limitaciones funcionales importantes en la extremidad afectada, que pueden ser de carácter sensitivo, motor o ambas. La reconstrucción nerviosa de las extremidades inferiores es un desafío quirúrgico para el cirujano por la dificultad técnica y la gran demanda de conocimiento que requieren.

Presentamos la experiencia en reconstrucción nerviosa de los miembros inferiores en el Hospital Universitario Clínica San Rafael en Bogotá (Colombia) y en el Hospital Manuel Gea González en México D.F, (México), y por primera vez, la neurotización sensitiva del nervio safeno interno al nervio tibial posterior

Material y método. Recopilamos información de 9 pacientes con lesiones nerviosas de los miembros inferiores, las más representativas según ubicación y etiología, que acudieron a la clínica especializada de nervio periférico, 3 en el Hospital Manuel Gea González y 6 en el Hospital Universitario Clínica San Rafael, y que requirieron reconstrucción nerviosa microquirúrgica.

Resultados. En todos los casos hubo recuperación funcional y/o sensitiva de la extremidad afectada. Describimos por primera vez la neurotización sensitiva del nervio safeno interno al tibial para recuperación de sensibilidad de la planta del pie.

Conclusiones. Cuanto más proximal es la lesión, más tarda su recuperación. La neurotización sensitiva del nervio safeno interno al nervio tibial es un procedimiento efectivo. El uso de diferentes técnicas quirúrgicas favorece una adecuada reconstrucción nerviosa. Lesiones con evolución menor de 1 año y brechas nerviosas menores de $6 \mathrm{~cm}$ son factores de buen pronóstico para la recuperación de los pacientes.

Palabras clave Miembro inferior, Reconstrucción nerviosa, Nervio sural, Microcirugía, Transferencia tendinosa

\section{Nivel de evidencia científica Recibido [esta versión] Aceptado}

4c Terapéutico

2 agosto/2019

25 noviembre/2019
Conflicto de intereses: Los autores declaran no tener ningún interés financiero relacionado con el contenido de este artículo. Financiación: No hubo fuentes externas de financiación para este trabajo.

\footnotetext{
Cirujano Plástico, Estético y Reconstructivo, Director de la Clínica de Parálisis Facial y Nervio Periférico, Hospital Universitario Clínica San Rafael, Bogotá, Colombia.

** Médico General, Medico Hospitalario del Servicio de Cirugía Plástica, Hospital Universitario Clínica San Rafael, Bogotá, Colombia.

*** Médico Residente de Cirugía Plástica, Hospital General Manuel Gea González, México D.F., México.

**** Cirujano Plástico, Estético y Reconstructivo, Director de la Clínica de Parálisis Facial y Nervio Periférico, Hospital General Manuel Gea González,
} México D.F., México.

Background and objective. The nerve injuries in the lower limb are a major problem because they cause functional limitation r both. The nerve reconstruction of lower limb is a challenging procedure because it requires huge knowledge of the pathology and urgeon expertise.

We present our experience in lower limb nerve reconstruction in the Universitary Hospital Clínica San Rafael in Bogotá (ColomIn addition, sensory neurotization of the internal saphenous nerve

Methods. Information was collected from 9 patients with nerve injuries of the lower limbs, the most representative according to ctiology, who attended the specialized clinic of peipheral nerve, 3 at the Manuel Gea González Hospital and 6 at the

Results. In all cases, functional and/or sensory recovery of the affected limb was obtained. The sensory neurotization of the inter-

Conclusions. The closer the lesion is, the longer it takes to recover. Sensory neurotization of the internal saphenous nerve to the tibial nerve is an effective procedure. The use of different surgical techniques favors adequate nerve reconstruction. Lesions with evoof good prognosis for the recovery of patients.
Key words Lower limb, Nerve reconstruction, Sural nerve, Microsurgery, Tendon transfer

\section{Level of evidence Received [this version]}

Therapeutic

2 Augost/2019 25 November/2019 


\section{Introduccion}

Las lesiones nerviosas motoras y sensitivas en el miembro inferior, desafortunadamente, han ido en ascenso debido al aumento de los accidentes de tránsito, de las lesiones ocasionadas por terceros, por arma cortopunzante o proyectil de arma de fuego, generando en el individuo un severo compromiso en la funcionalidad de la extremidad al quedar comprometida la sensibilidad, la motricidad o ambas, lo que conlleva una importante discapacidad a quienes las padecen, con limitación de sus actividades de la vida diaria y para su normal desarrollo dentro de la sociedad. Desde el siglo XVII se comenzó a hablar acerca de las lesiones nerviosas y las importantes repercusiones que estas ocasionan, pero no fue hasta la primera guerra mundial, en 1914,cuando por la cantidad y severidad de los traumas nerviosos, se comenzó a pensar en la forma de reconstruir estas lesiones para devolver a la persona afectada su funcionalidad. ${ }^{(1)}$

En Latinoamérica no existe un estudio que muestre la estadística de estas lesiones, pero en Europa sabemos que el 2-3\% de los traumas severos de miembros inferiores (entendiendo por severo cuando hay lesiones conjuntas de músculo, hueso y tejido blandos), tienen lesión nerviosa asociada, ${ }^{(2)}$ y que la mayoría no se diagnostica a tiempo o se deja su reconstrucción para el final.

Los nervios que con mayor frecuencia se ven comprometidos cuando ocurre un trauma de los miembros inferiores son el nervio peroneo y el ciático, seguidos por los nervios femoral y tibial que presentan el mismo porcentaje de lesión; esto se atribuye a su distribución anatómica a través del miembro inferior, que lo hace especialmente susceptible de sufrir traumatismos. ${ }^{(3)}$

A diferencia de la reconstrucción nerviosa del plexo braquial y sus nervios, en la que a pesar de padecer lesiones muy altas existen nervios donantes aledaños (en cue1lo, hombro o tórax) que nos ayudan a trasmitir información supliendo la perdida, en el miembro inferior estos donantes son escasos. Además en esta zona, cuanto más altas sean las lesiones, la recuperación funcional será de peor pronóstico por los largos recorridos que debe tomar la regeneración nerviosa. ${ }^{(3)}$

En el presente estudio mostramos la experiencia de 2 centros hospitalarios, el Hospital Manuel Gea González en México D.F. (México) y el Hospital Universitario Clínica San Rafael en Bogotá (Colombia) en el manejo de lesiones nerviosas en el miembro inferior. Estos 2 centros tienen clínicas especializadas en nervio periférico de las que proceden los casos que mostraremos, todos ellos creemos que relevantes en esta patología en el miembro inferior; además ambos centros brindan colaboración académica interinstitucional y estudios constantes sobre esta patología, y el Hospital Manuel Gea González en asociación con la Universidad Nacional Autónoma de México, tiene un programa de formación de alta especialización en parálisis facial y nervio periférico.

\section{Material y método}

Recolectamos información de 9 casos en total: 3 del Servicio de Cirugía Plástica del Hospital Manuel Gea González y 6 del Servicio de Cirugía Plástica del Hospital Universitario Clínica San Rafael. Tomamos los casos más representativos para poder tener una serie de casos variados que incluyera diferentes tipos de lesiones y manejos.

Catalogamos el estudio como una investigación retrospectiva, descriptiva, tipo serie de casos. Todos los pacientes presentaron lesión severa de miembro inferior por accidente de tránsito o por lesión por proyectil de arma de fuego o por lesión con arma cortopunzante, con lesión importante de tejidos blandos, muscular y en algunos casos ósea; todos con lesión nerviosa concomitante.

La reparación nerviosa se realizó como última etapa reconstructiva, habiendo solucionado previamente los defectos óseos musculares, vasculares, etc., y mediante técnica microquirúrgica en los dos centros mencionados. Valoramos la información de las historias clínicas, el seguimiento en el tiempo para ver su evolución y recopilamos los datos para realizar el presente estudio.

Explicamos detalladamente en primer lugar los 6 casos del Hospital Universitario Clínica San Rafael (HUCSR) y luego los 3 casos del Hospital General Manuel Gea González. En la Tabla I presentamos un resumen de las características de los pacientes y en la Tabla II los resultados obtenidos después del tratamiento quirúrgico.

Caso 1. Paciente de 47 años de edad que presentó herida por arma cortopunzante en cara póstero-medial, tercio medio, de pierna izquierda, al ser agredido en un robo. Fue atendido en otra institución del país, en donde le realizaron exploración quirúrgica con tenorrafia de músculos tibial posterior y flexor largo del hallux, reparación de arteria tibial posterior y, según el paciente, reconstrucción del nervio tibial posterior a este nivel.

El paciente acude a la clínica de nervio periférico del hospital a los 4 años de la lesión por presentar dolor neuropático quemante en tobillo y anestesia completa de la planta del pie izquierdo. Preservaba movimientos completos de dorsiflexión y plantiextensión del pie, con evidencia clínica de atrofia de músculos intrínsecos de la planta del pie izquierdo. La electromiografía muestra conducción nerviosa adecuada en la musculatura profun- 
Experiencia multicéntrica en reconstrucción nerviosa del miembro inferior

Tabla I. Características de la población de estudio. Rango de edad 16- 47 años (media 31.5 años). M: masculino (100\% hombres)

\begin{tabular}{|c|c|c|c|c|c|c|}
\hline Paciente & Edad & Género & Causa & Evolución & Procedimiento & Inicio de recuperación \\
\hline 1 & 47 & M & $\begin{array}{l}\text { Herida por arma } \\
\text { cortopunzante }\end{array}$ & 4 años & $\begin{array}{l}\text { Resección neuroma, Neurotización } \\
\text { sensitiva de nervio sural y peroneo } \\
\text { superficial a nervio tibial posterior }\end{array}$ & 6 meses \\
\hline 2 & 19 & M & $\begin{array}{l}\text { Herida por proyectil } \\
\text { de arma de fuego }\end{array}$ & 6 meses & $\begin{array}{l}\text { Neurolisis, } \\
\text { Puente con injerto de nervio sural }\end{array}$ & 10 meses \\
\hline 3 & 27 & M & Accidente de tránsito & 7 meses & $\begin{array}{c}\text { Neurolisis, } \\
\text { Puente con injerto de nervio sural, } \\
\text { Transferencia tendinosa de tibial } \\
\text { posterior }\end{array}$ & 4 meses \\
\hline 4 & 21 & M & $\begin{array}{l}\text { Herida por arma } \\
\text { cortopunzante }\end{array}$ & 22 días & $\begin{array}{l}\text { Neurolisis, } \\
\text { Injerto de fascia lata }\end{array}$ & 2 meses \\
\hline 5 & 33 & M & Caída & 15 días & $\begin{array}{l}\text { Neurolisis, Transferencia tendinosa de } \\
\text { tibial posterior, } \\
\text { Injerto de fascia, Puente con injerto de } \\
\text { nervio sural }\end{array}$ & 2 meses \\
\hline 6 & 16 & M & Caída de bicicleta & 4 meses & $\begin{array}{c}\text { Neurolisis, } \\
\text { Puente con injerto de nervio sural, } \\
\text { Neurotización de nervio safeno inter- } \\
\text { no a nervio tibial posterior }\end{array}$ & 7 meses \\
\hline 7 & 30 & M & $\begin{array}{l}\text { Herida por proyectil } \\
\text { de arma de fuego }\end{array}$ & 1 día & $\begin{array}{l}\text { Puente con injerto de nervio sural, } \\
\text { Neurotización de nervio peroneo } \\
\text { superficial al profundo }\end{array}$ & 4 meses \\
\hline 8 & 40 & M & $\begin{array}{l}\text { Herida por proyectil } \\
\text { de arma de fuego }\end{array}$ & 5 meses & $\begin{array}{l}\text { Neurolisis, Neurotización de nervio } \\
\text { gastrocnemio medial al profundo }\end{array}$ & 4 meses \\
\hline 9 & 39 & M & $\begin{array}{l}\text { Herida por proyectil } \\
\text { de arma de fuego }\end{array}$ & 3 meses & $\begin{array}{l}\text { Neurolisis, Neurotización de nervio } \\
\text { gastrocnemio medial al profundo }\end{array}$ & 5 meses \\
\hline
\end{tabular}

Tabla II. Resultados

\begin{tabular}{|c|c|}
\hline PACIENTE & RESULTADO \\
\hline 1 & $\begin{array}{ll}\text { - } & \text { Mejoría del dolor en un } 100 \% \\
\text { - } & \text { Recuperación sensitiva de S3 (inicial S0), tanto en la zona lateral como medial de la planta del pie } \\
\text { - } & \text { Sin afectación importante en áreas donantes de injertos nerviosos }\end{array}$ \\
\hline 2 & $\begin{array}{l}\text { - } \quad \text { Mejoría del dolor neuropático de la rodilla } \\
\text { - } \quad \text { Activación muscular del recto femoral M4 y recuperación en la sensibilidad del muslo y hasta tercio medio de } \\
\text { pierna derecha } 14 \text { meses }\end{array}$ \\
\hline 3 & $\begin{array}{ll}\text { - } & \text { Dorsiflexión del pie a los } 4 \text { meses } \\
\text { - } & \text { Reinervación M3 a los } 18 \text { meses } \\
\text { - } & \text { Logró sensibilidad del dorso del pie S3 del ramo superficial } \\
\text { - } & \text { El ramo profundo sensitivo no se activó }\end{array}$ \\
\hline 4 & $\begin{array}{ll}\text { - } & \text { Movimiento sutil de dorsiflexión } \\
\text { - } & \text { Plantiextension sutil (M2) y mejoría de la sensibilidad (S2) } \\
\text { - } & \text { El paciente continúa en vigilancia postoperatoria } \\
\end{array}$ \\
\hline 5 & $\begin{array}{l}\text { - } \quad \text { Movilidad de la transferencia tendinosa del músculo tibial posterior a los } 2 \text { meses } \\
\text { - } \quad \text { Activación del músculo tibial anterior a los } 10 \text { meses, logrando reinervación muscular M4 y sensitiva S3 }\end{array}$ \\
\hline 6 & $\begin{array}{ll}\text { - } & 7 \text { meses inicio contracción músculos gastrocnemios } \\
\text { - } & 10 \text { meses inicio contracción músculo tibial anterior } \\
\text { - } & 15 \text { meses máxima recuperación M2 en dorsiflexion y plantiextensión y S3 de sensibilidad plantar. }\end{array}$ \\
\hline 7 & $\begin{array}{l}\text { - } \quad 4 \text { meses inicia dorsiflexion del pie } \\
\text { - } \quad 7 \text { meses contracción muscular M5 y sensibilidad S4 }\end{array}$ \\
\hline 8 & $\begin{array}{l}\text { - } \quad 4 \text { meses inicia dorsiflexión del pie } \\
\text { - } \quad \text { El paciente continúa en vigilancia postoperatoria }\end{array}$ \\
\hline 9 & $\begin{array}{ll}\text { - } & 5 \text { meses inicia dorsiflexión } \\
\text { - } & 8 \text { meses máxima dorsiflexión M2-M3. Sensibilidad máxima de S3 en dorso del pie }\end{array}$ \\
\hline
\end{tabular}


da y superficial de la pierna izquierda, con signos de degeneración nerviosa en los músculos intrínsecos flexores de la planta del pie izquierda, sin placas neuromotoras en los mismos. Los potenciales sensitivos mostraron anestesia completa de la planta del pie con sensibilidad normal en el dorso. No se evidencian signos de ulceras o lesiones cutáneas en la piel de la planta de pie izquierdo.

Con esta información se decide llevar a exploración quirúrgica para tratar de realizar neurolisis y/o trasferencias sensitivas a fin de recobrar la sensibilidad y mejorar el dolor neuropático. No es objetivo recobrar la musculatura motora porque al paciente no le afectaba su deambulación, además de por no tener ya placas neuromotoras recuperables.

Bajo anestesia general y uso de monitoreo nervioso intraquirúrgico, se incide sobre cicatriz previa de pierna para exploración del nervio tibial posterior a ese nivel, encontrando un cuerpo extraño de consistencia dura que envolvía al nervio tibial posterior. Mediante disección meticulosa, se evidencia que correspondía a una bolsa de plástico de solución salina que habían acondicionado como tubo neural para tratar de guiar los cabos seccionados del nervio tibial posterior (Fig. 1). Se retiró la bolsa observando que no había unión nerviosa, con neuroma en el cabo proximal del nervio y tejido fibrótico en el distal y reacción inflamatoria importante alrededor del ner- vio. Se retira el tejido fibrótico de alrededor de los cabos y el neuroma del proximal hasta observar tejido nervioso sano, apareciendo un espacio entre los dos cabos de $7 \mathrm{~cm}$ aproximadamente. Se realiza terapia antineuroma de los cabos y con el monitoreo nervioso se verifica que los ramos motores de la pierna siguen indemnes. Se cierra esta incisión.

Posteriormente, se ubica el nervio sural ipsilateral a través de una incisión póstero-lateral en el tercio distal de la pierna izquierda, y con otra en la parte anterior y distal de la pierna, el nervio peroneo superficial, ramo sensitivo, para así liberarlos meticulosamente logrando su máxima longitud. Se realiza incisión a nivel del tunel de tarso del pie izquierdo, el cual se libera y se ubica el nervio tibial posterior antes de entrar por él; se corta distalmente el nervio sural traccionándolo hacia medial a través de túnel subcutaneo, sacándolo por la incisión del túnel del tarso y al nervio peroneo superficial se le realiza un túnel subcutáneo también, para sacarlo por la misma incisión. Así tenemos los dos nervios al lado del nervio tibial posterior; lo seccionamos a este nivel y realizamos la neurotización sensitiva término-terminal de los dos nervios a este cabo distal, suturándolos con nylon 9-0 (Fig. 2). Se evidencia que no exista tensión de la sutura y que haya vitalidad de los nervios. Cierre y férula posterior a 90 grados del pie durante 1 mes.

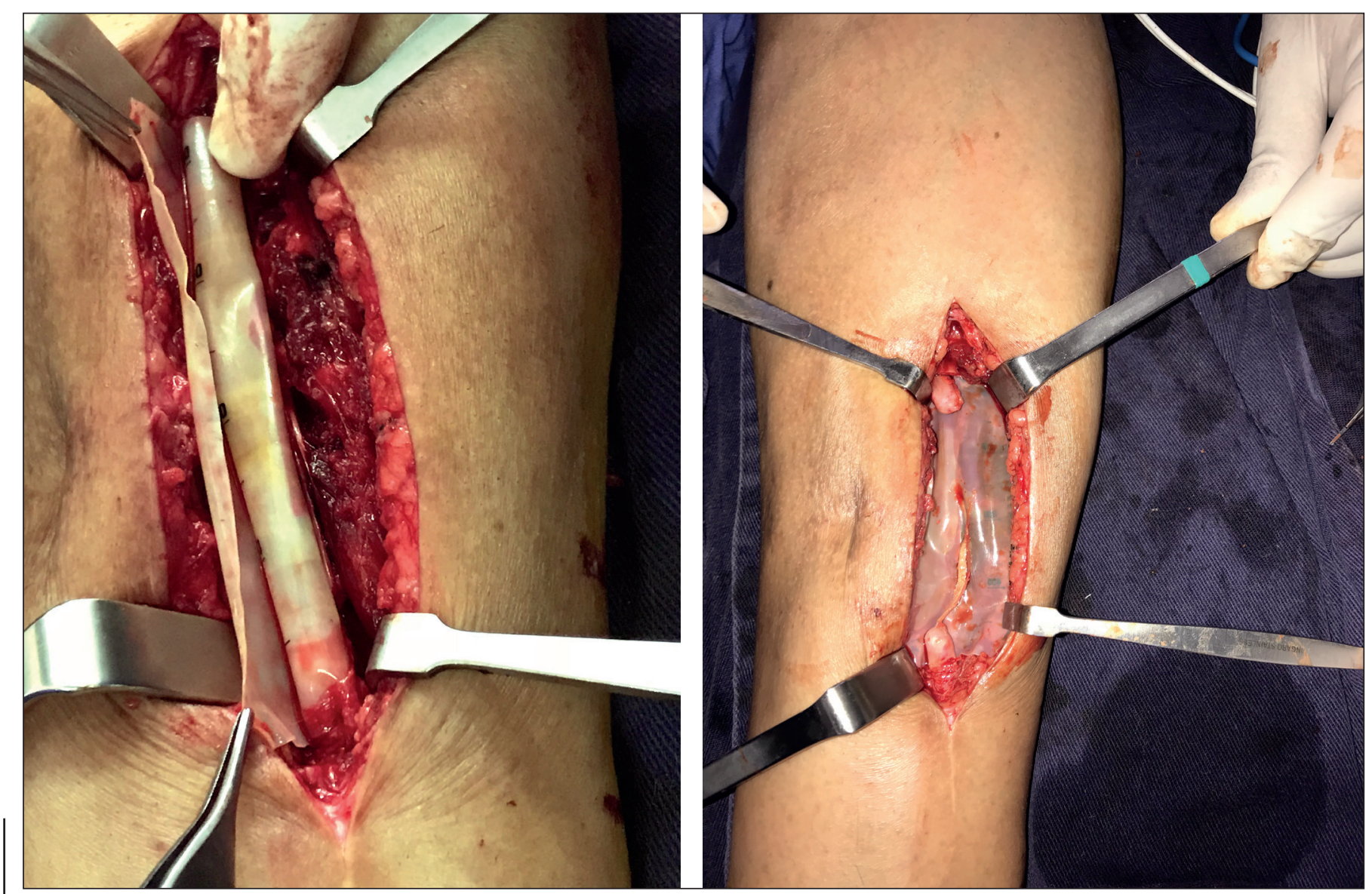

Figura 1. A. Se observa la bolsa de solución salina envuelta que usaron como tubo neural de forma improvisada extrainstitucionalmente. B. Se abre la bolsa y se observa el nervio tibial posterior seccionado con un brecha nerviosa de $7 \mathrm{~cm}$. 


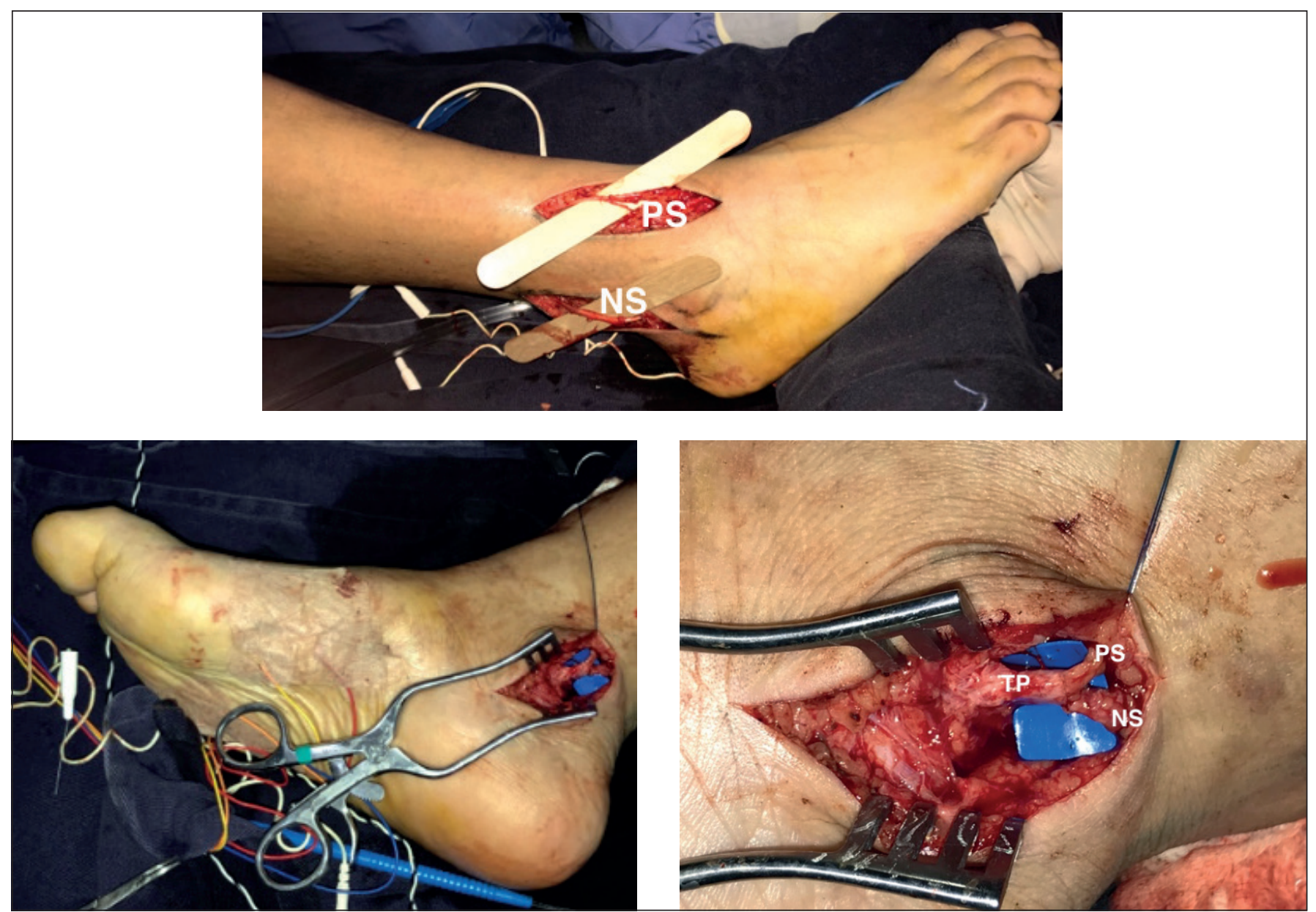

Figura 2. A. Se diseca y ubica la rama superficial del nervio peroneo superfial (PS) y retromaleolar externa al nervio sural (NS). B. Se realiza túnel subcutáneo anterior y posterior y se trasponen estas ramas disecadas en una incisión retromaleolar interna, ubicando al nervio tibial posterior antes de entrar al túnel del tarso. C. Se realiza neurorrafia término-terminal entre la rama superficial del nervio peroneo superficial y el nervio sural de forma proximal y el nervio tibial posterior de forma distal.

En el control a los 8 dias el paciente refería mejoría en un $100 \%$ del dolor neuropático que aquejaba a nivel del tobillo izquierdo. Se continuó seguimiento del caso con inicio de parestesia en planta del pie a los 6 meses, que siguió con Tinnel y al año presentaba una recuperación sensitiva de S3 (inicial S0), tanto en la zona lateral como medial de la planta del pie sin afectación importante en las zonas sacrificadas de los nervios donantes.

Caso 2. Paciente de 19 años de edad que acude a la Clínica de Nervio Periférico por presentar dificultad en la marcha. Refiere que 6 meses antes sufrió herida por proyectil de arma de fuego en la cadera derecha, con orificio de entrada a nivel de la cresta iliaca derecha y salida a nivel de la ingle ipsilateral. Fue atendido de urgencia en otra institución donde le realizan tratamiento ortopédico de la fractura de la cresta iliaca, le prescriben antibioticoterapia durante unos días y le dan salida sin percatarse de la lesión nerviosa que sufría el paciente, refiriéndole que la alteración en su marcha era por dolor secundario al impacto del proyectil en la cadera.

De forma ambulatoria, el paciente acude a su médico general ya sin dolor pero con persistencia de su dificultad en la marcha; se le realiza electromiografía que evidencia lesión en el nervio femoral derecho, motivo por el cual es remitido a nuestro Servicio.

Encontramos un paciente con imposibilidad para la extensión de la rodilla derecha, con reflejo patelar abolido y dolor quemante a nivel de la cara interna de la rodilla derecha, con anestesia de la cara ántero-medial del muslo y medial de la pierna ipsilateral. La electromiografía refleja lesión parcial del nervio femoral derecho a nivel del canal inguinal, de sus ramos superficiales, sin signos de reinervación, lesionando completamente músculo recto femoral y sartorio, vasto externo y medio parcialmente y vasto medial sin alteración, además de anestesia del dermatoma del nervio safeno interno.

Con esta información se decide exploración quirúrgica de la zona bajo anestesia general. Es llevado a procedimiento encontrando gran fibrosis perilesional del nervio femoral derecho a nivel de la ingle. Se realiza resección de la fibrosis y neurolisis, encontrando lesión completa del nervio femoral derecho en su mitad superficial mientras que la profunda estaba integra (Fig. 3). Después de retirar el tejido fibrótico de los cabos nerviosos se produjo un espacio internervioso de $5 \mathrm{~cm}$, por 


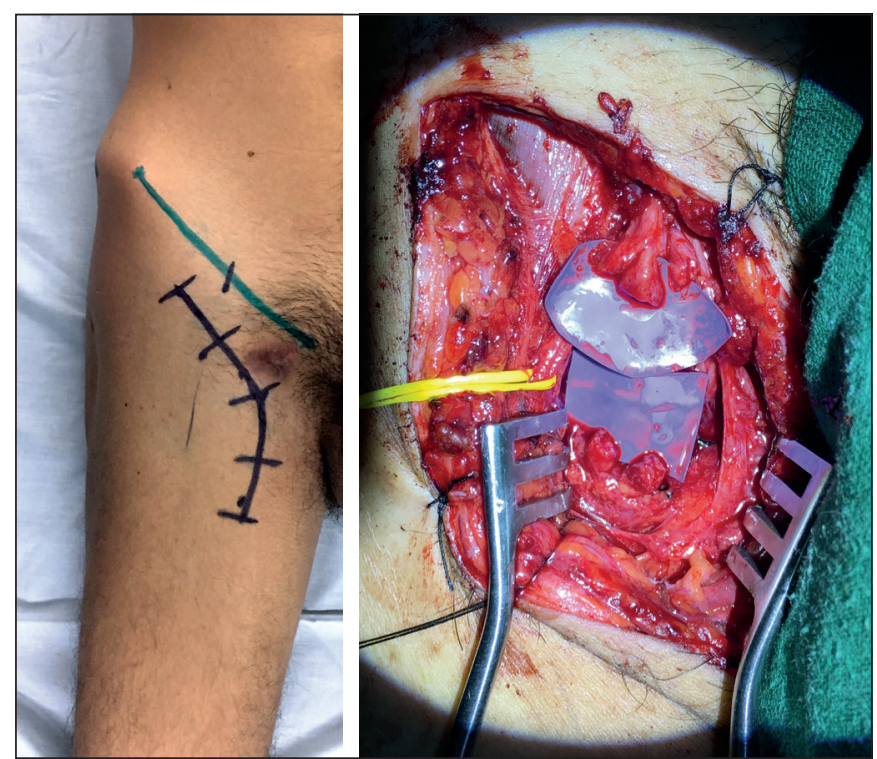

Figura 3. A. Se diagrama el ligamento inguinal derecho y la incisión en forma de $\mathrm{J}$ para ubicar el nervio femoral. B. Tras neurolisis, se identifica que 3 ramos superficiales del nervio femoral están seccionados. Con la liga amarilla se repara y protege la parte profunda del nervio femoral derecho que está integra.

lo que se decide realizar 3 puentes con injerto de nervio sural tomado de la pierna izquierda, reconstruyendo el nervio femoral con este injerto mediante suturas término-terminales con nylon 9-0 (Fig. 4). Cierre y alta al día siguiente de la intervención.

El paciente evoluciona adecuadamente, desapareciendo el dolor neuropático de su rodilla inmediatamente. Seguimos la regeneración nerviosa con signo de Tinel adecuado, evidenciando inicio de activación muscular del recto femoral a los 10 meses de la intervención. A los 14 meses el paciente ya presentaba activación muscular del recto femoral M4 y recuperación de la sensibilidad del muslo y hasta tercio medio de la pierna derecha.

Caso 3. Paciente de 27 años de edad que 7 meses antes sufre accidente de tránsito al ir conduciendo una motocicleta y estrellarse contra otro vehículo, presentando fractura de tibia y peroné en tercio proximal de pierna derecha. Es tratado en el Hospital Universitario Clínica San Rafael donde le colocan un tutor externo de forma provisional, durante unas semanas y luego un clavo endomedular de forma definitiva. Presenta secundariamente imposibilidad en la dorsiflexión del pie, por lo que se le prescribe férula a 90 grados y fisioterapia. Tras varios meses en terapia y al no ver mejoría, le envían a nuestro Servicio. Aporta electromiografía que demuestra lesión del nervio peroneo común alto, sin signos de reinervación.

Se decide llevar al paciente a exploración quirúrgica bajo anestesia general y estimulación nerviosa intraquirúrgica. Se realiza incisión en la cara lateral del tercio superior de la pierna derecha, sobre la cabeza del peroné. Se diseca y encuentra el nervio peroneo común con

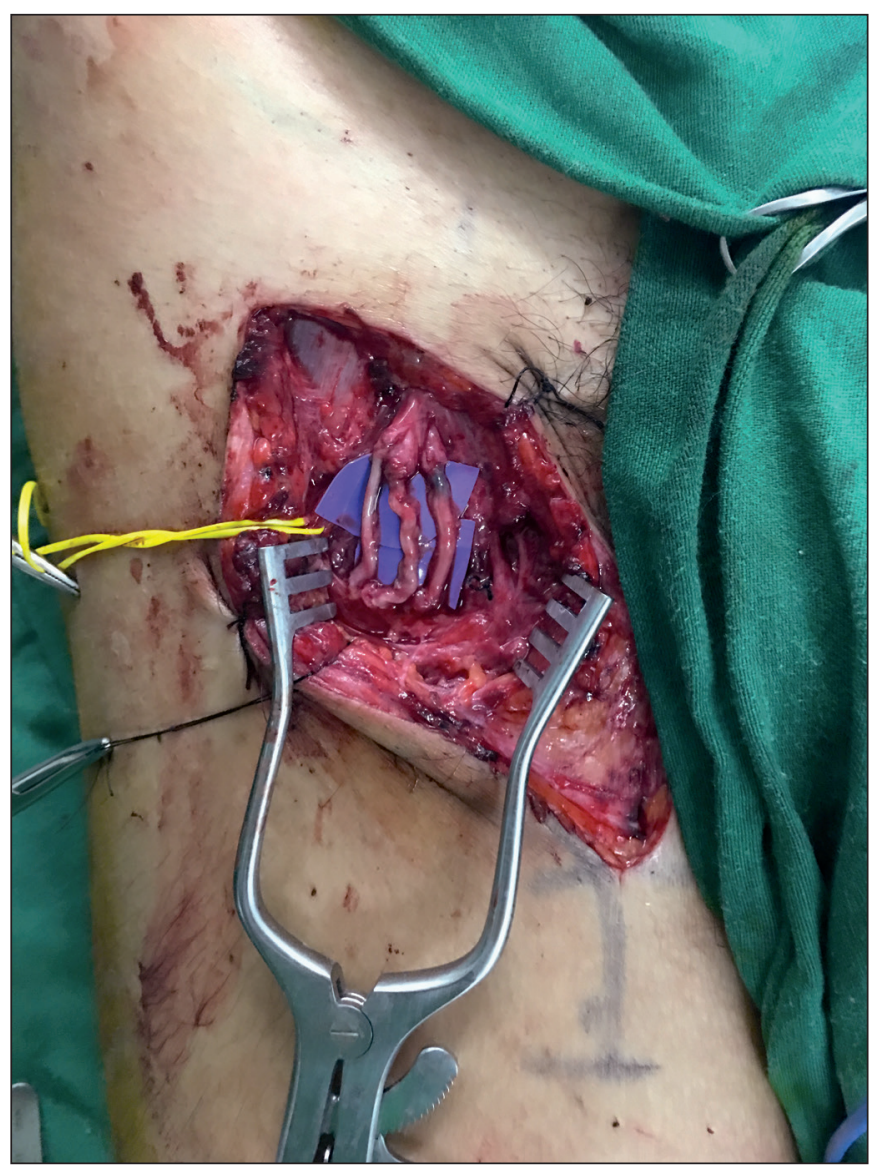

Figura 4. Con la ayuda del injerto de nervio sural se reconstruye el nervio femoral usando 3 puentes nerviosos, con neurorrafia término-terminal.

francos signos de inflamación y congestión, con moteado nervioso en una porción de $3 \mathrm{~cm}$ aproximadamente, inmediatamente antes de bifurcarse en superficial y profundo (Fig. 5). Con monitoreo nervioso, usando electrodo tripolar y bipolar, se ubica la zona nerviosa que no conduce, correspondiente a zona moteada del nervio. Se realiza neurolisis y resección de esta zona, dejando secundariamente una desunión nerviosa de $4 \mathrm{~cm}$. Se toma injerto de nervio sural de la pierna izquierda y se realizan 5 puentes nerviosos para reconstruir el nervio peroneo común con sutura término-terminal usando nylon 9-0 y sin tensión (Fig. 6).

Distalmente se realiza trasferencia tendinosa de músculo tibial posterior pasándolo a través de la membrana interósea y uniéndolo con tornillo de biotenodesis a cuboides y colocando férula interna del cuello del pie derecho a 90 grados que se mantiene durante 5 semanas sin apoyo. El paciente es seguido en evolución durante 18 meses, activándose la trasferencia tendinosa a los 4 meses y logrando con ella la dorsiflexión del pie; sigue con reinervación con signo de Tinel sín complicaciones y terapia física, empezando activación de músculo tibial anterior a los 14 meses de la intervención para lograr reinervación M3 a los 18 meses. Logró sensibilidad del dorso del pie S3, del ramo superficial; el ramo profundo sensitivo no se activó. 

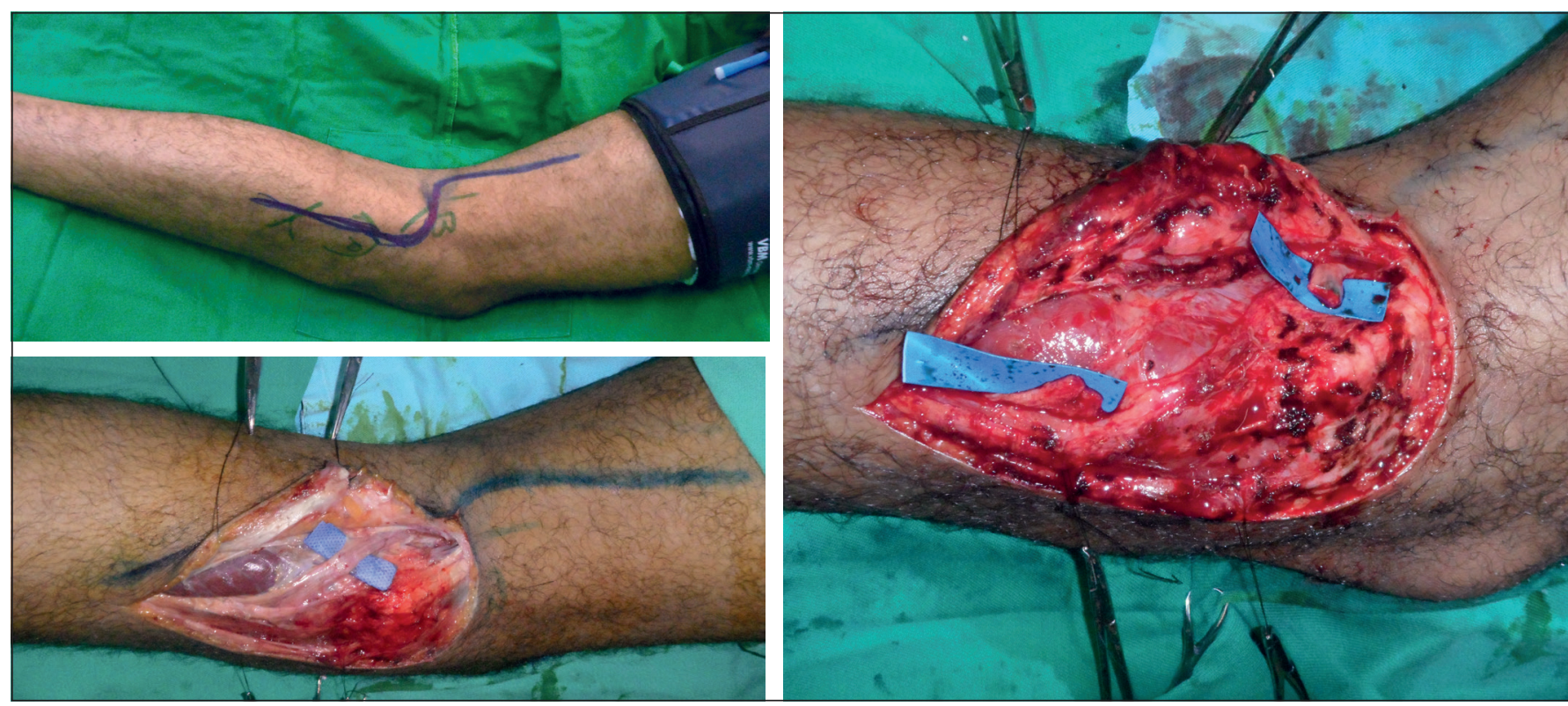

Figura 5. A. Incisión utilizada en la cara póstero-lateral de la pierna para la ubicación del nervio peroneo común y sus bifurcaciones. B. Se ubica el nervio peroneo común con gran neuroma que no trasmitía información. C. Se retira neuroma dejando brecha nerviosa posterior de $3 \mathrm{~cm}$.

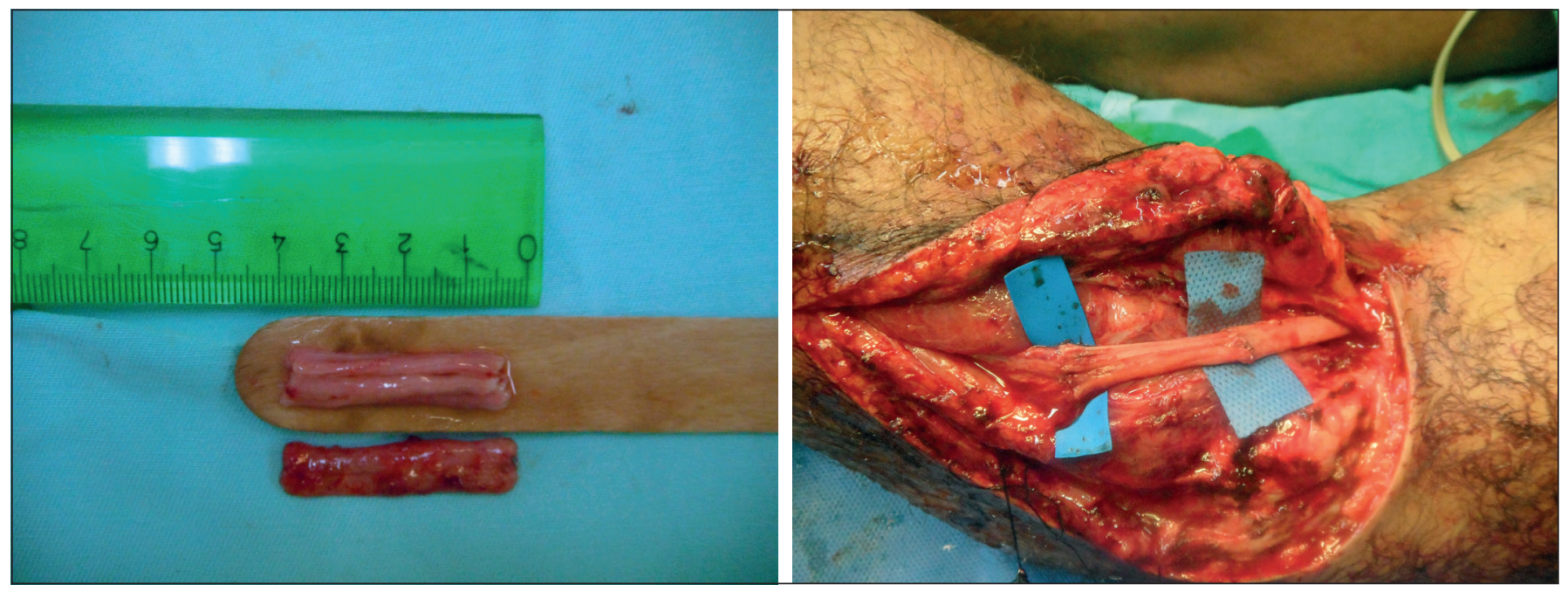

Figura 6. A. Se toma injerto de nervio sural, se divide en 5 tiras de $4 \mathrm{~cm}$ cada una y se unen entre si para reconstruir el segmento del nervio peroneo común resecado (parte inferior del bajalenguas). B. Se toma el injerto y se traspone a la lesión, realizando neurorrafia término-terminal con nylon 9-0.

Caso 4. Paciente de 21 años de edad valorado intrahospitalariamente por limitación de la dorsiflexión del pie derecho por sufrir, 22 días antes, herida por arma cortopunzante al ser agredido por un tercero a nivel del tercio medio de la cara medial de la pierna derecha. Se le diagnostica sección completa de la arteria tibial posterior a ese nivel, por lo que es intervenido quirúrgicamente por el Servicio de Cirugía Vascular que practica recanalización de la arteria y que, dado el gran edema secundario, decide realizar fasciotomías para evitar la aparición de un síndrome compartimental. El paciente es monitorizado posteriormente, evidenciando un adecuado pulso pedio y requirió varios lavados quirúrgicos posteriores con desbridamiento del soleo y del tibial posterior parcialmente por necrosis muscular secundaria.

Encontramos un paciente con un aceptable estado general, adecuada perfusión distal de sus extremidades pero con limitación a la dorsiflexión y plantiextensión del pie derecho, además de anestesia de la planta del pie ipsilateral. No se realiza electromiografía porque era evidente que la magnitud del trauma habría lesionado el nervio tibial posterior, y aunque no había lesión directa del nervio peroneo, la falta de movimiento podría explicarse por el gran edema secundario que tuvo el paciente (neuroapraxia). Se decide llevarlo a cirugía para explorar el nervio y valorar el posible compromiso del nervio peroneo.

Se accede a través de una fasciotomía medial realizada previamente. Se diseca cuidadosamente encontrando gran fibrosis perilesional en torno al paquete tibial posterior. Bajo disección microquirúrgica se realiza neurolísis del nervio tibial posterior, teniendo mucho cuidado con la arteria que se encontraba al lado para no lesionarla nuevamente. Retirando tejido fibrótico perilesional, se libera el nervio sin complicaciones, no evidenciando sección del mismo, pero sí adelgazamiento al retirar la 
gran fibrosis que lo cubría. Se continua su recorrido hasta el túnel del tarso, el cual se libera también profilácticamente. Como se produjo tanta necrosis muscular y posterior fibrosis, y al tener ya liberado e íntegro el nervio, se decide protegerlo envolviéndolo con fascia lata tomada del muslo derecho. Se envuelve cuidadosamente todo el nervio en los dos tercios distales de la pierna derecha, realizando una especie de tubo neural con la fascia que se cierra con monocryl 4-0 y se cierra la fascia de la pierna. Se cubre la fasciotomía con injertos de piel parcial tomados del muslo, evitando tensión de la pierna. Se feruliza el miembro durante 4 semanas.

El paciente sigue vigilancia ambulatoria, refiriendo a los 2 meses de la cirugía disestesias en la planta del pie y movimiento sutil de dorsiflexión. A los 4 meses, inicio de la plantiextensión sutil (M2) y mejoría de la sensibilidad (S2).

Caso 5. Paciente de 33 años de edad que presentó 15 días antes, caída de su pierna derecha en un hueco, con trauma en el tercio superior de la cara externa de la misma. El paciente no acude inmediatamente a urgencias,
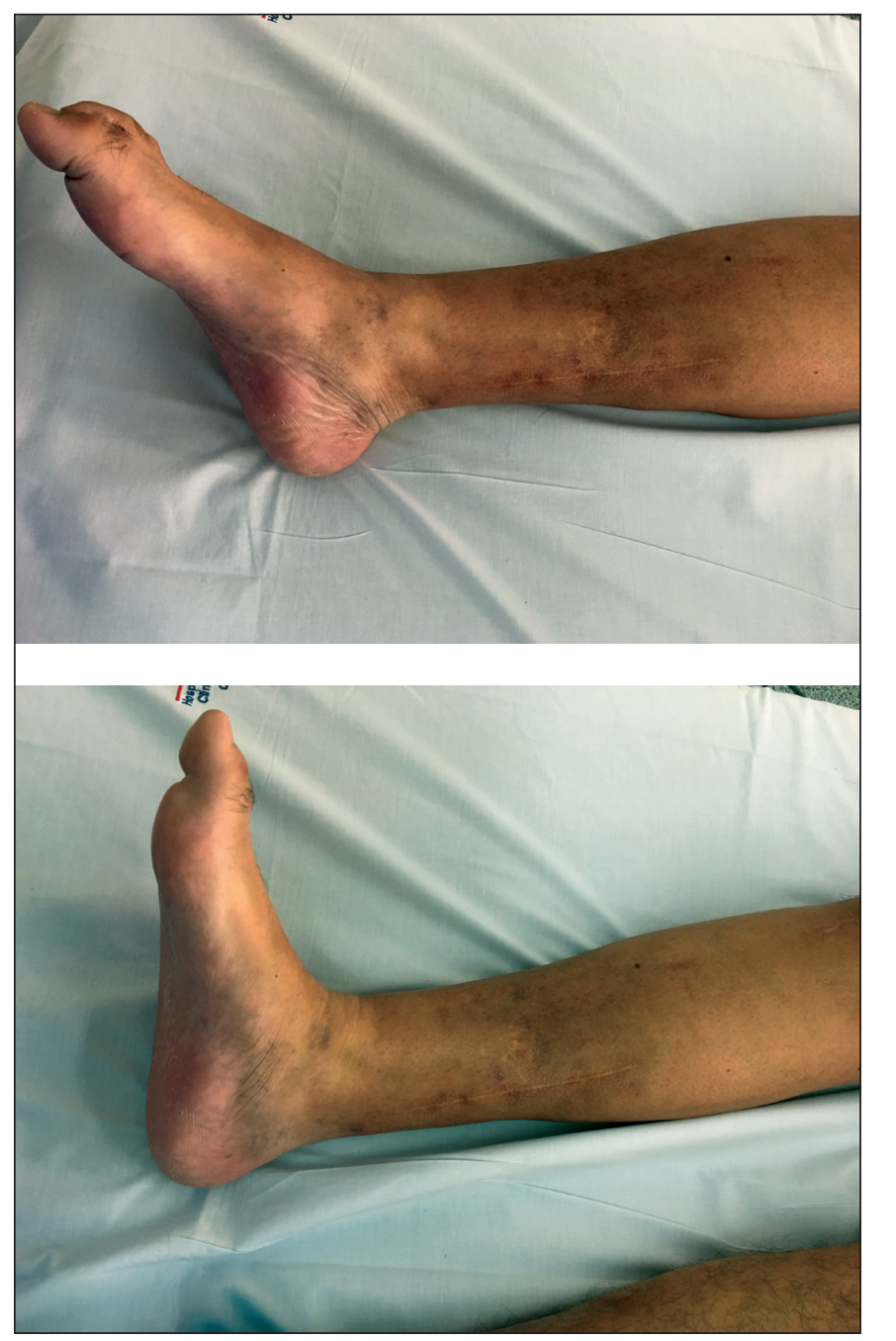

Figura 7. A. Se observa activación de la transferencia tendinosa del músculo tibial posterior al anterior a los 2 meses, tanto en plantiextensión como en $\mathrm{B}$, dorsiflexión del pie. y continuó cojeando. Acude al Servicio de Ortopedia de forma ambulatoria, donde le realizan radiografía que evidencia fractura por avulsión de la cabeza del peroné derecho. Lo manejan solo con inmovilización, pero por limitación en la dorsiflexion del pie, nos lo remiten posteriormente.

Encontramos limitación a la dorsiflexión del pie derecho con anestesia del dorso del mismo. Se decide llevarlo a cirugía para exploración.

Se realiza incisión en la cara lateral del tercio superior de la pierna derecha, sobre la cabeza del peroné. Se diseca meticulosamente, encontrando el nervio peroneo común íntegro pero con fibrosis importante, además de un fragmento óseo de la cabeza del peroné avulsionado, que se encontraba inmediatamente encima del nervio, comprimiéndolo a este nivel. Se realiza resección del fragmento óseo y neurolisis del nervio, retirando la fibrosis con lo que se pierden dos fascículos nerviosos superficiales del peroneo común. Se toma segmento del injerto del nervio sural izquierdo y se reponen con él estos dos fascículos de $3 \mathrm{~cm}$ aproximadamente cada uno, uniéndolos con sutura término-terminal con nylon 9-0. Se toma segmento de fascia profunda de la pierna a este nivel y se envuelve esta zona reconstruida del nervio para protección. Se cierra por planos. Distalmente, en la misma pierna, se realiza transferencia tendinosa del músculo tibial posterior a través de la membrana interósea y se une al tendón del músculo tibial anterior. Se abre en dos el tendón del tibial posterior y se une cada cabo a todos los tendones de músculo flexor largo de los dedos y al tibial anterior, dejándolos con adecuada tensión y logrando posición del tobillo a 90 grados con ferulización interna del tobillo (Fig. 7).

Se realiza vigilancia postoperatoria evidenciando movilidad de la transferencia tendinosa del músculo tibial posterior a los 2 meses, con disestesias en dorso de pie a los 8 meses y activación del músculo tibial anterior a los 10 meses, logrando reinervación muscular M4 y sensitiva S3.

Caso 6. Paciente de 16 años de edad que presentó cuadro de 4 meses de evolución desde una caída de bicicleta, a consecuencia de la cual sufre trauma contundente en el muslo izquierdo con fractura de fémur. Es atendido en otra institución donde le realizan reducción de la fractura de fémur con clavo endomedular y le dan salida con inmovilización y terapia física. Cuando retiran la férula, se dan cuenta de que presenta limitación en la marcha por pie caído, por lo que lo remiten a nuestro centro.

Encontramos franca limitación para la marcha por pie caído izquierdo, con anestesia en todo el pie, y flexo-extensión de la rodilla sin limitación. 

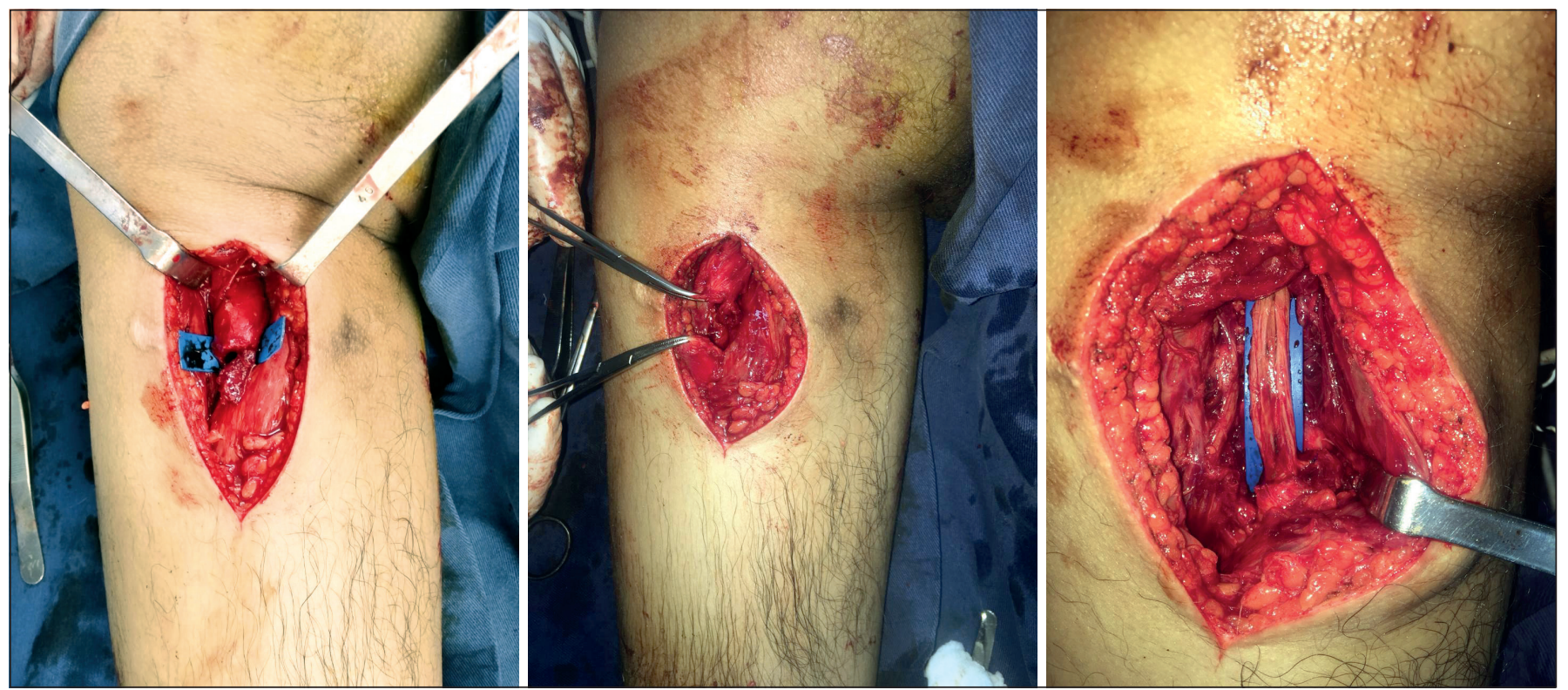

Figura 8. A. Se encuentra cabo proximal seccionado del nervio ciático en tercio superior del muslo izquierdo. B. Se ubica el cabo distal del mismo nervio seccionado con una brecha nerviosa de $6 \mathrm{~cm}$. C. Se realizan puentes nerviosos múltiples para la reconstrucción del nervio, de $7 \mathrm{~cm}$, uniéndolos término-terminal con nylon 9-0.

La electromiografía evidencia lesión aguda del nervio ciático izquierdo en tercio medio, sin signos de reinervación. Se decide llevar al paciente a cirugía para exploración quirúrgica bajo anestesia general.

Se realiza incisión sobra la cara posterior del tercio medio del muslo izquierdo. Se diseca por planos, encontrando el nervio ciático completamente seccionado, unidos los dos cabos, proximal y distal, al foco de fractura del fémur. Se realiza su liberación viendo gran neuroma del cabo proximal y fibrosis del distal; se reseca el neuroma y la fibrosis hasta visualizar fascículos nerviosos íntegros y vitales, dejando un espacio internervioso de $6 \mathrm{~cm}$. Se toma injerto de nervio sural de las dos piernas, realizando un puente nervioso de $7 \mathrm{~cm}$ con 7 fascículos, con neurorrafia término-terminal con nylon 9-0 (Fig. 8).

Como la lesión del nervio era tan alta y comprometía todo el nervio, no se podía realizar ningún tipo de trasferencia tendinosa. La rodilla no estaba comprometida porque la lesión estaba después de dar las ramas para los músculos isquiotibiales. Pero para tratar de recuperar más pronto la sensibilidad de la planta del pie, se decidió realizar una neurotización sensitiva desde el nervio safeno interno hasta el nervio tibial posterior. Se buscó el nervio safeno en la cara medial de la rodilla y el tibial posterior antes de entrar al canal del tarso. Se tomó un injerto nervioso de aproximadamente $20 \mathrm{~cm}$, se pasó subcutáneamente de punto a punto y se unió término-terminal al safeno interno y término-lateral al tibial posterior (Fig. 9).

El paciente permaneció hospitalizado durante 24 horas. Se siguió progreso con signo de Tinnel adecuado. A los 7 meses se evidencia inicio de contracción en los músculos gastrocnemios y a los 10 meses en el musculo tibial anterior. A los 15 meses se logra máxima recupera- ción de M2 en dorsiflexión y plantiextensión del pie izquierdo y sensibilidad en la planta del pie de S3. Aunque el resultado no fue el mejor, el paciente está conforme.

Caso 7. Paciente de 30 años de edad con cuadro de 1 día de evolución por herida por proyectil de arma de fuego a nivel del tercio superior de la pierna derecha a consecuencia de la cual presenta imposibilidad para la dorsiflexión del pie y anestesia en la cara ántero-lateral de la pierna y del dorso del pie. Es llevado a cirugía con ayuda de monitorización nerviosa intraquirúrgica para explorar la lesión de forma más adecuada. Se realiza un barrido inicial que evidencia lesión del nervio peroneo profundo derecho. A través de una incisión en forma de $\mathrm{S}$ itálica, desde la fosa poplítea hasta la cabeza del peroné, se explora toda la zona encontrando la sección completa del nervio en mención. Se realiza desbridamiento y limpieza de la zona y del nervio hasta encontrar los cabos vitales óptimos para la reconstrucción. Se evidencia una brecha nerviosa de $3 \mathrm{~cm}$, por lo que no es posible una neurorrafia sin tensión, ante lo cual se decide tomar injerto de nervio sural y llevar a cabo la reconstrucción con puentes nerviosos, la cual se realiza adecuadamente. Además, para potenciar el resultado, se decide neurotización con injerto nervioso látero-lateral del nervio peroneo superficial al profundo, próximo al nervio del musculo tibial anterior.

Se coloca férula durante 4 semanas; el paciente fue dado de alta a las 48 horas de la intervención y se siguió controlando de forma ambulatoria. A los 4 meses inicia recuperación de la dorsiflexión, completándolo a M5 a los 7 meses (Fig. 10). Además, recuperó sensibilidad en el dorso del pie (S4), aunque en la zona del peroneo superficial esta fue menor (S3). 


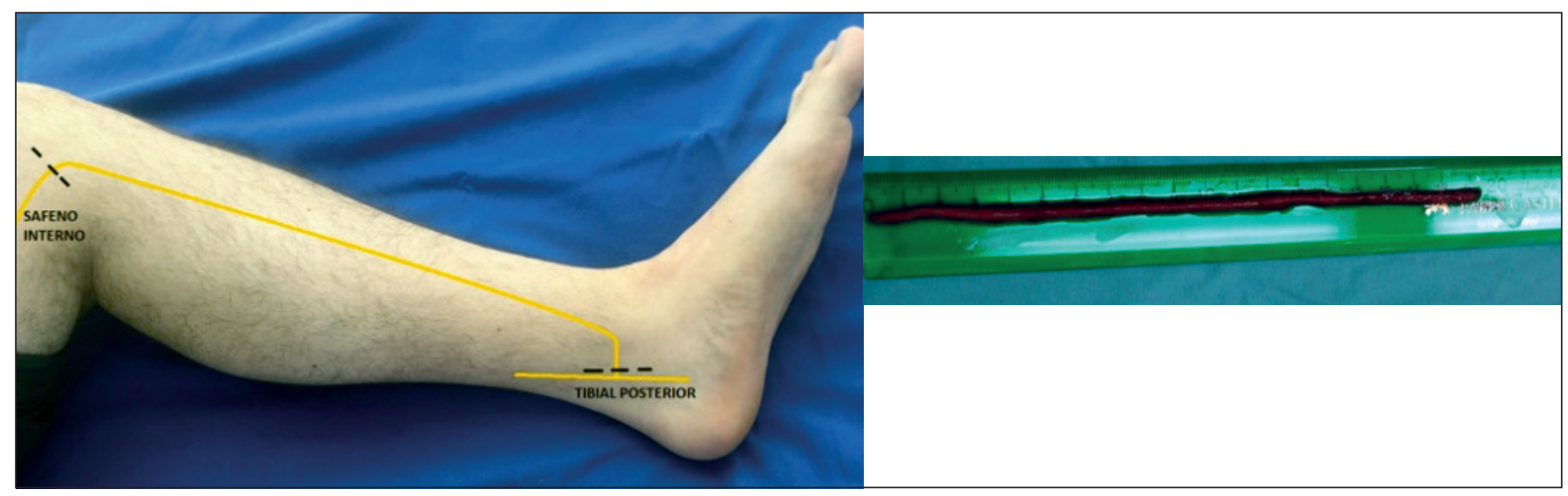

Figura 9. A. Neurotización sensitiva del nervio safeno interno, ubicado en la cara interna de la rodilla, al nervio tibial posterior, ubicado 2 cm proximal a su ingreso al túnel del tarso. B. El injerto de nervio sural de aproximadamente $20 \mathrm{~cm}$ se utiliza para esta neurotización, término-terminal con el safeno y término-lateral con el tibial posterior. Se realiza túnel subcutáneo uniendo estas dos incisiones.

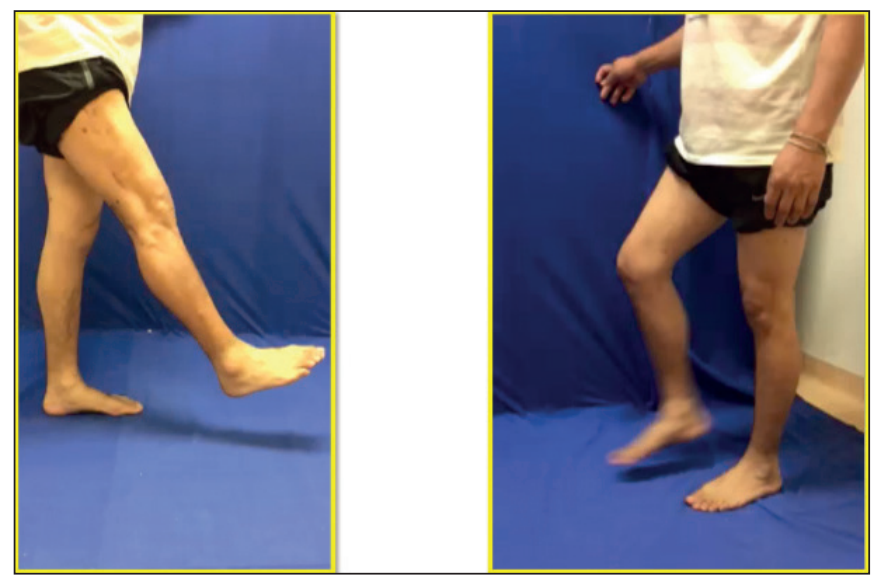

Figura 10. A y B. A los 7 meses de la intervención se logra dorsiflexión y plantiextensión en M5 de la extremidad afectada.

Caso 8. Paciente de 40 años de edad con cuadro de 5 meses de evolución tras herida por proyectil de arma de fuego en la pierna izquierda. Fue atendido en otra institución donde atendieron la urgencia y realizaron control de daños. Es remitido al Hospital Gea González por imposibilidad de la dorsiflexión del pie izquierdo asociada a marcha en estepaje.

La electromiografía preoperatoria evidenció lesión del nervio peroneo común. Se decide llevar al paciente a cirugía para exploración, y se realiza el mismo abordaje del caso anterior para exponer de forma adecuada el nervio tibial y sus bifurcaciones terminales. Se observa integridad o continuidad del nervio peroneo común y de sus ramas profunda y superficial con bastante tejido fibrótico perilesional. Se realiza neurolisis minuciosa de la zona y retirada del tejido fibrótico; posteriormente con la ayuda de monitorización nerviosa intraquirúrgica se muestra una adecuada trasmisión nerviosa al realizar la neurolisis de los potenciales evocados motores, por lo que se considera suficiente esta maniobra para reconstruir el nervio. Para maximizar los resultados se ubica el nervio del gastrocnemio medial y se neurotiza al nervio peroneo profundo de forma término-lateral (Fig. 11). Las neurorrafias se hicieron con nylon 10-0.

También se coloca férula durante 4 semanas y se hace seguimiento del paciente de forma ambulatoria. A los 4 meses empieza con la dorsiflexión del pie (M3) y se encuentra en su proceso de recuperación.

Caso 9. Paciente de 39 años de edad de edad con cuadro de 3 meses de evolución tras trauma en tercio distal del muslo derecho por proyectil de arma de fuego. Es atendido extrainstitucionalmente en urgencias y remitido
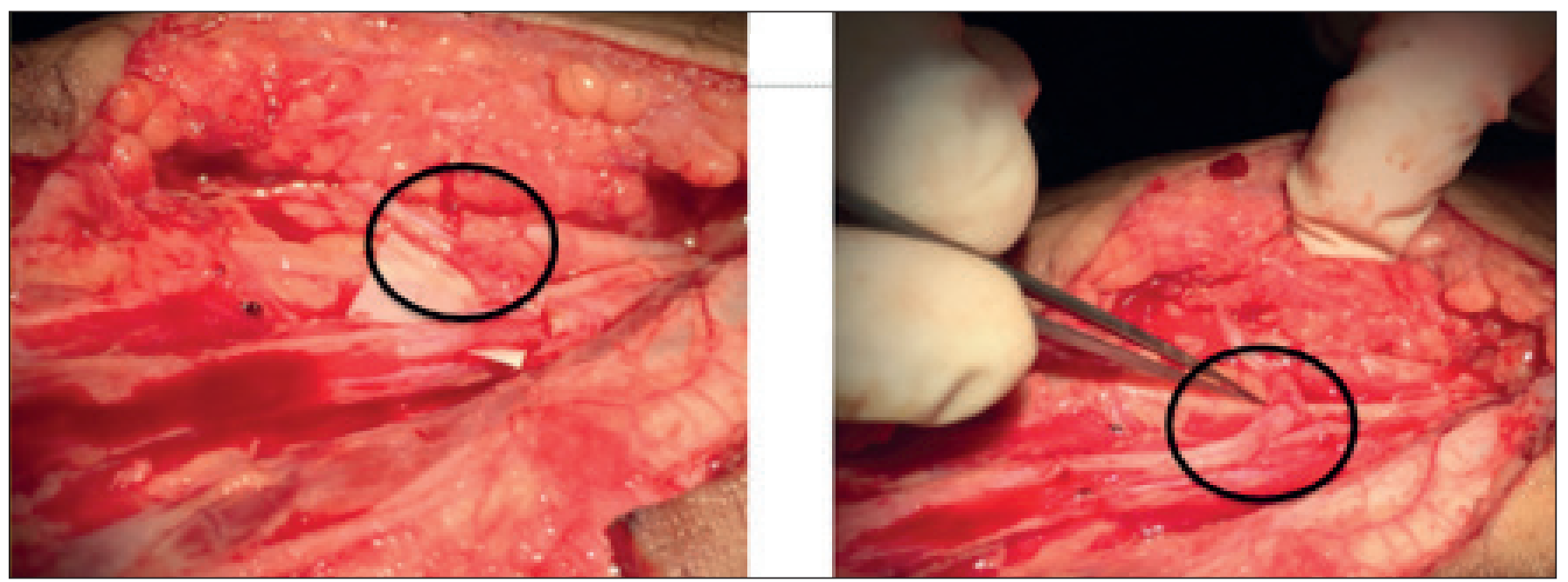

Figura 11. A. Se ubica el nervio del gastronemio medial y se prepara para su transferencia. B. Se diseca y logra su mayor longitud, transfiriéndolo al nervio peroneo profundo de forma término-lateral. 
a la clínica de nervio periférico del Hospital Manuel Gea González por marcha en estepaje.

En la valoración se encuentra cicatriz en tercio distal cara lateral del muslo derecho, con imposibilidad para la dorsiflexión y eversión del pie, anestesia de la cara ántero-lateral de la pierna y del dorso del pie. La electromiografía reporta lesión parcial del nervio ciático distal a este nivel, sin paso de información por el nervio peroneo común.

Es llevado a cirugía con el mismo abordaje del caso anterior, encontrando nervio ciático distalmente, unos 5 $\mathrm{cm}$ superior a la fosa poplítea derecha, con fibrosis importante y neuroma intranervioso de $5 \mathrm{~cm}$ aproximadamente, sin pérdida de la continuidad.

Se realiza neurolisis minuciosa perilesional e intranerviosa, y mediante potenciales evocados motores con monitorización nerviosa intraquirúrgica se evidencia trasmisión de la señal de forma distal por el nervio, por lo que no se realizan injertos nerviosos (Fig. 12). Como el nervio tibial posterior estaba íntegro, se realiza neurotización del nervio gastrocnemio medial al nervio peroneo profundo de forma término-lateral con nylon 10-0, sin complicaciones.

Se coloca férula que se mantiene durante 4 semanas y se da salida al paciente a las 48 horas de la cirugía. Inicia dorsiflexión a los 5 meses, alcanzando a los 8 meses dorsiflexión máxima de M2-M3; la sensibilidad del dorso del pie se logra a S3.

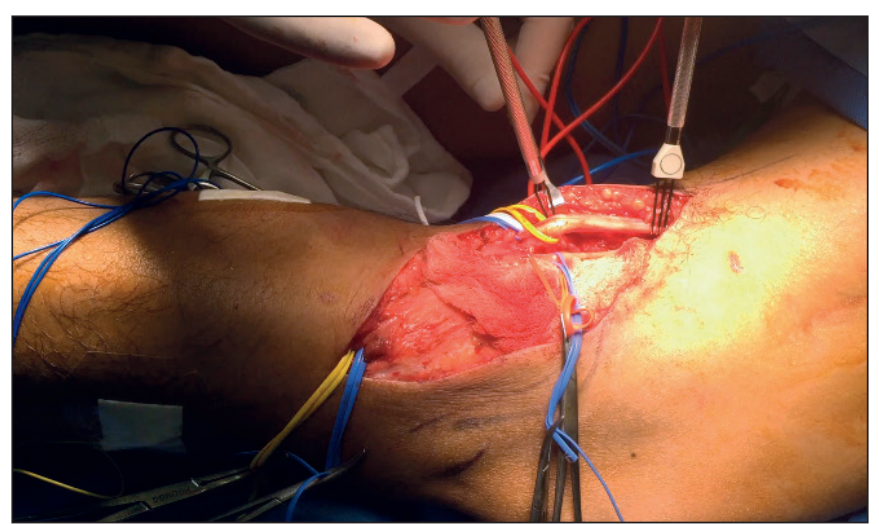

Figura 12. Ubicando el nervio ciático distalmente en el muslo y realizando neurolisis minuciosa. Se realiza monitorización nerviosa intraquirúrgica posterior, con electrodos bi y tripolares, verificando trasmisión exitosa nerviosa.

\section{Discusión}

En Europa, la lesión nerviosa del miembro inferior se da aproximadamente en el 2-3\% de pacientes con trauma severo de la extremidad. ${ }^{(2)}$ Aunque no tenemos estadísticas fehacientes en Latinoamérica, sabemos que en la última década la reconstrucción nerviosa microquirúrgica ha aumentado, quizá porque ya se tomo conciencia de la importancia de tratar estas lesiones.
Quisimos unir los casos más representativos de reconstrucción nerviosa del miembro inferior por diferentes causas en 2 centros especializados en nervio periférico, uno en Colombia y otro en México. Estos 2 centros, dirigidos desde hace varios años por los autores principales del presente estudio, Dr. Cárdenas y Dr. Rojas, bridan formación de conocimiento en este tema e intercambio constante del mismo. Existen en Latinoamérica pocos centros dedicados al estudio del nervio periférico, por lo que la unión de sus experiencias enriquece el presente artículo; además, el Dr. Cárdenas coordina el curso de alta especialización en parálisis facial y nervio periférico en México, en el que varios residentes y especialistas de los centros en mención se han entrenado.

Características importantes para el buen pronostico de una recuperación nerviosa es el que se trate de pacientes jóvenes y con lesiones de menos de 1 año de evolución, circunstancias que se daban en todos nuestros pacientes excepto en el caso 1, que llevaba 4 años de evolución, pero en el que la lesión era sensitiva, por lo que la recuperación fue exitosa.

Como está descrito en la literatura, el nervio peroneo común es el más afectado en el miembro inferior; en nuestros casos, 5 de los 9 pacientes tuvieron afectación de este nervio (55\%), lo que concuerda con lo publicado. ${ }^{(4)}$ En las diferentes series encontradas sobre tratamiento reconstructivo de este nervio, vemos diferentes alternativas quirúrgicas y diferentes resultados. Kim y $\mathrm{col}^{(4)}$ publican una de las series de casos más grande de lesión del nervio peroneo común, con buenos resultados y destacando una mejoría superior al $80 \%$ tras neurolisis y neurorrafias término- terminales y del $40 \%$ en reconstrucción con puente de injerto nervioso. Refieren también que las lesiones menores de $6 \mathrm{~cm}$ o por causa de sección traumática tienen mejor pronóstico que las lesiones mayores de $6 \mathrm{~cm}$ o por trauma contundente sin sección, sino por tracción. Las lesiones del nervio ciático altas son de peor pronóstico, lo cual concuerda con nuestros casos 6 y 9, en los que la máxima recuperación lograda fue M2-M3 en la dorsiflexión del pie, por presentar lesiones altas.

En la última década se han popularizado las neurotizaciones en el miembro inferior, más sabiendo las largas distancias que debe recorrer una regeneración nerviosa, por lo que las lesiones más proximales en el miembro inferior son las de peor pronóstico. Así, tratando de acortar distancias o evitar que la placa neuromotora muera antes de que llegue la información de un nervio reconstruido, las neurotizaciones han tomado un papel importante. También lo son las transferencias tendinosas (de músculo tibial posterior), que aunque no son una técnica nueva, ya que la primera reportada fue en 1933 por Ober, ${ }^{(5)}$ 
son una herramienta importante en este tipo de lesiones. Las primeras publicaciones de esta técnica la utilizaban como tratamiento paliativo o como último recurso en pacientes con deformidades instauradas, como secuelas a largo plazo de lesiones nerviosas, parálisis cerebrales o postraumáticas. Se describieron 2 técnicas, la popularizada por Ober, o circunferencial, ya que realizaba el paso del tendón del tibial posterior subcutáneamente alrededor de la tibia hasta fijarlo al tercer metatarsiano; y la de Whatkins, en 1954, o interósea, porque hacía el paso del tibial posterior a través de la membrana interósea. ${ }^{(6)}$ Ambas técnicas tienen ventajas y desventajas. La circunferencial tiene más fuerza de palanca pero menor excursión al movimiento; la interósea tiene un eje de movimiento más recto, pero puede producir adherencias cicatriciales y riesgo de lesión del paquete peroneo.

En la Clínica de Nervio Periferico del HUCSR hemos venido utilizando esta transferencia del músculo tibial posterior de forma habitual, aunque es muy útil cuando no han funcionado las reconstrucciones nerviosas o cuando el paciente llega con más de 1 año con el pie caído. En el Servicio se utiliza en lesiones del nervio peroneo común. Sabemos que la recuperación de este nervio es deficiente por múltiples factores, aunque le técnica quirúrgica utilizada se realice bien. Y mientras llega la información necesaria para realizar la dorsiflexión del pie, existe el riego de crear tobillos anquilosados o con dolor crónico, por lo que el uso de una férula interna funcionante, como la proporcionada con la transferencia del musculo tibial posterior, es ideal.

Hemos realizado la fijación de este tendón de las dos formas descritas, al hueso por medio de un tornillo de biotenodesis y con fijación a los tendones extensores del pie, sin diferencias significativas. Cuando lo hacemos de esta última forma, o tendón - tendón, siempre dividimos el tendón del tibial posterior en dos, una mitad la unimos al tendón del tibial anterior y la otra mitad al flexor largo del hallux y a los tendones extensores largos de los dedos, de esta forma equilibramos el movimiento a neutro y por tenodesis preservamos el movimiento de los dedos. Nos hemos dado cuenta de que normalmente la trasferencia tendinosa se activa a los 2 meses, lo que hace que el paciente se reincorpore más rápido a su vida, sienta menos frustración por la demora en la regeneración nerviosa y por ende haga mejor la terapia física postoperatoria. Además cuando la funcionalidad muscular aparece por la reconstrucción nerviosa, se ve reflejada con mayor fuerza en el movimiento y con movimientos con mayor arco de movilidad en todas las direcciones.

Las neurotizaciones son muy útiles también siempre que sean posibles; trasferir información del nervio tibial posterior al peroneo profundo y/o superficial de forma distal a la lesión, ayudará a una recuperación mas rápida, que es lo que siempre buscamos. Esto se realiza en los 2 Servicios y, como vimos en los últimos 3 casos, ayudó a lograr una mejor y más rápida recuperación. Exige un conocimiento anatómico exacto de las zonas a tratar y el uso de monitorización nerviosa intraquirúrgica, nos aporta exactitud en la búsqueda y evaluación de nuestras estructuras nerviosas.

Un punto a resaltar es que aunque reconstruir las lesiones motoras es de vital importancia para la marcha del paciente, también lo es el lograr una adecuada sensibilidad de la planta del pie. La anestesia crónica de la planta del pie se comporta como una neuropatía periférica crónica, como por diabetes, en la cual la falta de sensibilidad produce microtraumatismos y alteración en la barrera de protección de la piel, lo que conlleva ulceraciones y sobreinfecciones cutáneas con malposición del pie.(7) Por esto siempre tenemos que realizar una evaluación motora y sensitiva y tratar las dos lesiones de forma simultánea.

Koshima y $\operatorname{col}^{(8)}$ describen la restauración de la sensibilidad plantar con la trasferencia nerviosa del nervio peroneo profundo al nervio tibial en 2 pacientes con buenos resultados. Tung y $\operatorname{col}^{(9)}$ presentan la transferencia del nervio peroneo superficial al nervio tibial también. Y Rodríguez-Lorenzo y col ${ }^{(10)}$ hacen un estudio cadavérico de la factibilidad teórica de la neurotización combinada de la rama superficial del nervio peroneo superficial con el nervio sural al nervio tibial para lograr una mayor carga axonal y así mejores resultados sensitivos. Esto fue lo que realizamos en nuestro caso 1 con excelentes resultados. Y como innovación en nuestro caso 6 , realizamos la neurotización sensitiva del nervio safeno interno al nervio tibial antes de entrar al túnel del tarso, logrando recuperación de la sensibilidad plantar S3, dato que no hemos visto reportado previamente.

El uso de fascia protectora envolviendo los nervios severamente traumatizados es muy útil; nos ayuda a mantenerlos en un medio adecuado para su recuperación y regeneración además de evitar la posterior fibrosis perinerviosa cuando las estructuras vecinas están muy edematizadas y traumatizadas, como sucedía en nuestros casos 4 y 5 .

El uso de estimulación nerviosa intraquirúrgica es una herramienta muy útil en el planteamiento quirúrgico de este tipo de lesiones. Nos brinda información muy importante en cuanto al compromiso motor por medio de los potenciales evocados y sensitivos por medio de los somatosensoriales. ${ }^{(11)}$ Como vimos en nuestra serie de casos, los utilizamos en 6 casos (66\%), siendo especialmente útil en los casos 8 y 9 en los que después de la neurolisis evidenciamos paso de la información por el segmento nervioso, lo que corroboró que esa técnica por sí sola, fue suficiente para reconstruir el nervio. 
Los resultados de nuestros casos de lesión de nervio periférico en miembro inferior fueron muy variados, con resultados favorables en todos y tasas de éxito superiores al $80 \%$, cifra muy en concordancia y sintonía con la literatura revisada. ${ }^{(4,5,9)}$ La curva de aprendizaje en este tipo de lesiones es larga y quizá, como la patología no es tan prevalente, se demora en el tiempo. Además, debemos tener un conocimiento anatómico y fisiopatológico de la lesión nerviosa exacto para lograr adecuados resultados. Los estudios publicados no son tan extensos, con resultados variables entre los autores y el no tener nervios donantes tan suficientes como en el manejo del plexo braquial, nos obliga a jugar con la combinación de múltiples técnicas, como neurotizaciones, reconstrucciones locales con neurorrafias término-terminales o término-laterales y transferencias tendinosas, todas utilizadas en nuestros casos para lograr resultados confiables y duraderos.

\section{Conclusiones}

La reconstrucción microquirúrgica del nervio periférico en el miembro inferior es muy útil y presenta resultados confiables si se realiza la o las técnicas adecuadas en cada caso.

El uso intraoperatorio de monitorización de nervio periférico nos ayuda a la toma de decisiones durante la cirugía y al adecuado planteamiento de la misma, a la vez que nos da seguridad en lo que estamos haciendo.

La combinación de múltiples técnicas en la reconstrucción del nervio en miembro inferior ya sea mediante neurolisis, neurorrafias y puentes nerviosos con injertos de nervio, con transferencias tendinosas y/o neurotizaciones, nos ayuda a aumentar el nivel de éxito de la cirugía, y creemos que todo lo que hagamos en aras de restaurar la función motora y sensitiva de nuestros pacientes, nunca estará de más.

Cuanto más corto es el tiempo desde la lesión nerviosa (ideal si es menos de 1 año) hasta el momento de la reconstrucción, mejor será el pronóstico para su recuperación. Las brechas nerviosas menores de $6 \mathrm{~cm}$ también nos proporcionarán un mejor pronóstico. De igual forma influye la causa de la lesión, puesto que las secciones nítidas del nervio son también de mejor pronóstico mientras que las lesiones por tracción, como las ocasionadas por la avulsión de la cabeza del peroné, son de peor pronóstico. Toda lesión por encima de la rodilla ofrecerá también un pronóstico peor.

En el presente trabajo realizamos además un aporte a la comunidad científica describiendo la neurotización sensitiva del nervio safeno interno al nervio tibial como opción en el tratamiento de la anestesia plantar, con buenos resultados cuando tenemos pacientes con sección del ciático muy alta, solo teniendo como nervios donantes los emergentes del nervio femoral.

En nuestro caso, el engranaje y ayuda colaborativa entre dos instituciones dedicadas a una patología, como son el Hospital Universitario Clínica San Rafael de Bogotá y el Hospital General Manuel Gea González de México D.F. en cuanto al estudio y manejo del nervio periférico, resulta muy enriquecedor y nos impulsa y motiva a mejorar cada día.

\section{Dirección del autor}

Dr. Leonardo Rojas

Hospital Universitario Clínica San Rafael

Carrera 8 \# 17-45 sur

Bogotá - Colombia

Código postal: 110441

Correo electrónico: rojas.leonardo.md@gmail.com

Bibliografía

1. Mathes S, Nahai F. Plastic Surgery- Chapter one, General principles. Volumen 1, $5^{\text {a }}$ edición, EE.UU. Edit. Converse, 2005; Pp.719-743.

2. Huckhagel T, NüchternJ, Regelsberger J, Gelderblom $\mathbf{M}$, Lefering R. Nerve trauma of the lower extremity: evaluation of 60,422 leg injured patients from the TraumaRegister DGU ${ }^{\circledR}$ between 2002 and 2015, Scand J Trauma Resusc Emerg Med, 2018; 26(4): 1-8.

3. Beris A, Gkiatas I, Gelalis I, Papadopoulos D, Kostas-Agnantis I. Current concepts in peripheral nerve surgery. Eur $J$ Orthop Surg Tr. 2018; 29(2): 263-269.

4. Kim DH, Murovic JA, Tiel RL, Kline DG. Management and outcomes in 318 operative common peroneal nerve lesions at the Louisiana State University Health Sciences Center. Neurosurgery 2004; 54:1421-1429.

5. Ozkan T, Tunçer S, Oztürk K, Aydin A, Ozkan S. Surgical restoration of drop foot deformity with tibialis posterior tendon transfer. Acta Orthop Traumatol Turc 2007; 41(4):259-265.

6. Di Masi G, Socolovsky M, Bonilla G, Bataglia D. Transferencia tendinosa de tibial posterior en parálisis del nervio perneo común: ¿El fin del pie caído? Rev Argent Neuroc. 2014; 28 (2): 48-54.

7. Durval Campos Kraychete, Rioko Kimiko Sakata. Neuropatías Periféricas Dolorosas. Rev Bras Anestesiol. 2011; 61: 5: 351360 .

8. Koshima I, Nanba Y, Tsutsui T, Takahashi Y. Deep peroneal nerve transfer for established plantar sensory loss. J Reconstr Microsurg 2003;19(7):451-454.

9. Tung TH, Weber RV, Mackinnon SE. Nerve transfers for the upper and lower extremities. Oper Tech Orthop 2004;14:213222.

10. Rodríguez-Lorenzo A, Gago B, Pineda AF,et al. Superficial peroneal and sural nerve transfer to tibial nerve for restoration of plantar sensation after complex injuries of the tibial nerve: Cadaver feasibility study. J of Plast, Rec \& Aesth Surg 2011; 64: 1512-1516.

11. Papazian O. Indicaciones médicas y quirúrgicas de los potenciales evocados. Medicina (B.Aires). 2007; 67(6): 647-660. 
